\title{
The development and investigation of the psychometric properties of a burnout scale within a South African agricultural research institution
}

\begin{tabular}{|c|c|}
\hline \multicolumn{2}{|c|}{$\begin{array}{l}\text { Authors: } \\
\text { Doris N. Asiwe } \\
\text { Lené I. Jorgensen }^{1} \\
\text { Carin Hill }\end{array}$} \\
\hline \multicolumn{2}{|c|}{$\begin{array}{l}\text { Affiliations: } \\
{ }^{1} \text { WorkWell, Research } \\
\text { Unit for Economic and } \\
\text { Management Sciences, } \\
\text { North-West University, } \\
\text { Potchefstroom Campus, } \\
\text { South Africa }\end{array}$} \\
\hline \multicolumn{2}{|c|}{$\begin{array}{l}{ }^{2} \text { Department of Industrial } \\
\text { Psychology and People } \\
\text { Management, University of } \\
\text { Johannesburg, South Africa }\end{array}$} \\
\hline \multicolumn{2}{|c|}{$\begin{array}{l}\text { Correspondence to: } \\
\text { Lené Jorgensen }\end{array}$} \\
\hline \multicolumn{2}{|c|}{$\begin{array}{l}\text { Email: } \\
\text { lene.jorgensen@nwu.ac.za }\end{array}$} \\
\hline \multicolumn{2}{|c|}{$\begin{array}{l}\text { Postal address: } \\
\text { Private Bag X6001, Internal } \\
\text { Box } 114 \text {, Potchefstroom } \\
2520 \text {, South Africa }\end{array}$} \\
\hline \multicolumn{2}{|c|}{$\begin{array}{l}\text { Dates: } \\
\text { Received: } 17 \text { Jan. } 2014 \\
\text { Accepted: } 12 \text { May } 2014 \\
\text { Published: } 18 \text { Sept. } 2014\end{array}$} \\
\hline \multicolumn{2}{|c|}{$\begin{array}{l}\text { How to cite this article: } \\
\text { Asiwe, D.N., Jorgensen, } \\
\text { L.I., \& Hill, C. (2014). } \\
\text { The development and } \\
\text { investigation of the } \\
\text { psychometric properties } \\
\text { of a burnout scale within a } \\
\text { South African agricultural } \\
\text { research institution. } \\
\text { SA Journal of Industrial } \\
\text { Psychology/SA Tydskrif vir } \\
\text { Bedryfsielkunde, 40(1), Art. } \\
\text { \#1194, } 14 \text { pages. http:// } \\
\text { dx.doi.org/10.4102/sajip. } \\
\text { v40i1.1194 }\end{array}$} \\
\hline \multicolumn{2}{|c|}{$\begin{array}{l}\text { Copyright: } \\
\text { (C) 2014. The Authors. } \\
\text { Licensee: AOSIS } \\
\text { OpenJournals. This work } \\
\text { is licensed under the } \\
\text { Creative Commons } \\
\text { Attribution License. }\end{array}$} \\
\hline \multicolumn{2}{|l|}{ Read online: } \\
\hline 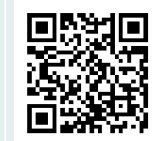 & $\begin{array}{l}\text { Scan this QR } \\
\text { code with your } \\
\text { smart phone or } \\
\text { mobile device } \\
\text { to read online. }\end{array}$ \\
\hline
\end{tabular}

Orientation: Burnout of employees is well documented within South Africa, but researchers have adapted imported instruments with a number of limitations. Therefore there is a need to develop a new instrument suitable for use in South Africa.

Research purpose: To give an overview of current burnout measures, identify gaps within the literature and develop a new burnout scale for use within South Africa. The research examined the construct validity, reliability, construct equivalence and item bias of this new scale and investigated any differences that exist in relation to demographic variables.

Motivation for the study: This study aimed to address various limitations regarding existing measures by developing a reliable and valid instrument for measuring burnout in South African employees that includes cognitive, physical and emotional (affective) components.

Research approach, design and method: This empirical, quantitative research study delivered a cross-sectional survey, including the burnout scale and a biographical data questionnaire, to 443 employees of an agricultural research institution. Items for the burnout scale were written based on a literature review.

Main findings: Exploratory factor analysis with target rotations resulted in a three-factor burnout model. Reliability analysis showed that all three scales (1) were sufficiently internally consistent and (2) showed construct equivalence for Black and White employees and speakers of Afrikaans and African languages. A practically significant difference in burnout levels was found in relation to age.

Practical/managerial implications: The scale can be used to assess burnout for different cultural groups within research-based institutions.

Contribution/value-add: This study contributes to knowledge regarding the burnout levels of employees in an agricultural research institution in South Africa and provides a new burnout scale that can be utilised in similar institutions.

\section{Introduction}

The term 'burnout' was coined in the United States in the mid-1970s and relates to difficulties in the employee-work relationship (Maslach \& Schaufeli, 1993). The association between employees and their working environment and the problems that result when this employeework relationship does not function as expected have been acknowledged as important characteristics of the work context (Maslach, Schaufeli \& Leiter, 2001). Burnout has been linked to various job-related behaviours such as health-related absences from work, work disabilities and decreased motivation (Ahola, Toppinen-Tanner, Huuhtanen, Koskinen \& Väänänen, 2009; Bekker, Croon \& Bressers, 2005).

Burnout was initially identified as a social issue by practitioners and social commentators with the highest level of interest, discussion and literature in people-oriented professions (Maslach \& Schaufeli, 1993). Another aspect worthy of note is that most of the initial burnout literature was non-empirical (Schaufeli \& Enzmann, 1998). The emphasis was on symptoms of burnout, which were derived from non-standardised examination and interpretation of case studies (Maslach \& Schaufeli, 1993). Consequently, despite the profusion of writing on burnout, there was 'not an early emphasis on developing theories of burnout and there was no conceptual framework for integrating and evaluating the various findings and proposed solutions' (Maslach \& Schaufeli, 1993, p. 5).

The nature of burnout research underwent a transformation during the subsequent developmental phases and the concept of burnout was extended to include occupations outside the human 
services. The move towards more empirical work was followed by both theoretical and practical contributions from the industrial-organisational field (Maslach et al., 2001). Burnout research therefore began to focus more on job factors rather than on other types of variables. Furthermore, the focus during the developmental phase was on empirical research and more productive, purposeful systematic and empirical research was produced and published (Maslach et al., 2001). This phase also offered different types of supporting evidence in the form of survey and questionnaire data, responses from interviewees and clinical case studies; consequently, standardised measures of burnout were developed. The existence of these measures provided researchers with more clear-cut definitions as well as tools to study the phenomenon (Maslach \& Schaufeli, 1993).

Following the development of concepts and assessment tools for burnout, burnout research, which was hitherto conducted exclusively in the United States of America (USA), was undertaken in various countries (Schaufeli \& Enzmann, 1998). These countries did not go through the pioneer phase of development and instead made use of the established burnout concepts and measures developed in the USA. The concept of burnout as operationalised by the Maslach burnout inventory (MBI) was therefore accepted in other countries (Maslach et al., 2001). The MBI dominated the field of burnout research to the extent that the definition of burnout that was implied in this instrument became the commonly accepted definition of burnout (Halbesleben \& Buckley, 2004; Schaufeli, 2003). For researchers using the MBI, burnout was defined as a condition characterised by emotional exhaustion, depersonalisation and reduced personal accomplishment (Maslach \& Jackson, 1981, 1986).

The consequence of this widespread use of the MBI was that the early debate regarding the conceptualisation of burnout was rather narrow and alternative measures of burnout were rarely developed (Maslach \& Schaufeli, 1993), hence the call by Schaufeli, Maslach and Marek (1993) for researchers to also focus on the development of other measures of burnout rather than focusing only on examining the psychometric properties of the MBI. According to Maslach and Schaufeli (1993, p. 16), 'many questions and controversies remain and much theorizing and research have yet to be done' concerning the concept of burnout. Since the call by Schaufeli et al. to expand burnout research, many more burnout measures have been developed. The most commonly used measures within burnout research focus on the dimensions of exhaustion, cynicism, professional efficacy and disengagement from a general job perspective.

In light of the abovementioned, the main objectives of this research study were to (1) give an overview of the current burnout measures being used in literature, (2) identify potential gaps within these measures, (3) address these gaps through the development of a new burnout scale, (4) investigate the psychometric properties of the burnout scale on a South African sample of employees, (5) examine the construct equivalence of the newly developed measure for use on a diverse range of employees within South Africa and (6) explore whether demographic variables influenced the degree of burnout within South African employees.

\section{Burnout defined}

Burnout is defined as a persistent, negative, work-related state in normal individuals that is primarily characterised by exhaustion, which is accompanied by distress, a sense of reduced effectiveness, decreased motivation and the development of dysfunctional attitudes and behaviours at work (Schaufeli \& Enzmann, 1998). Burnout is also defined as an erosion of engagement with the job (Maslach \& Leiter, 1997) or as being disengaged (Kahn, 1990). Kahn (1990) describes personal disengagement as an individual's uncoupling from the work role, simultaneous withdrawal and defence of their preferred self through the manifestation of behaviours that promote a lack of connection, physical, cognitive and emotional absence and passive, incomplete role performance (Kahn, 1990). To withdraw preferred dimensions involves removing personal, internal energies from physical, cognitive and emotional labours (Kahn, 1990). Burnout is also a metaphor that is commonly used to describe a state or process of mental exhaustion (Schaufeli \& Enzmann, 1998).

Similarly, Schaufeli and Greenglass (2001) define burnout as a state of physical, emotional and mental exhaustion that results from long-term involvement in work situations that are emotionally demanding. Maslach et al. (2001) point out that when people report burnout (whether in themselves or in others) they often refer to exhaustion. Exhaustion has therefore been both the most commonly reported as well as the most comprehensively studied component of burnout (Maslach et al., 2001). However, according to Maslach et al., placing too much emphasis on the exhaustion component of burnout could lead to difficulties in the conceptualisation of burnout. This is because exhaustion is not merely experienced, but also stimulates emotional and cognitive detachment from work. In fact, Rothmann (2003) states that constant exhaustion can result in individuals detaching themselves emotionally and cognitively from their work to the extent that they are so preoccupied that they are no longer sensitive to the needs of others or to the demands of the job. According to Hobfoll and Shirom (2000), burnout therefore consists of three closely interrelated factors: physical fatigue, emotional exhaustion and cognitive weariness.

According to Qiao and Schaufeli (2011), although the concept of 'burnout' was introduced over 30 years ago, its conceptualisation is still vehemently debated, as illustrated, for instance, by a special issue of Work $\mathcal{E}$ Stress (Cox, Tisserand \& Taris, 2005). A conceptual controversy exists as to whether burnout should be viewed as work-related exhaustion (Cordes \& Dougherty, 1993; Shirom, 1989) or a multidimensional construct that goes beyond mere exhaustion (Maslach \& Jackson, 1981; Schaufeli, Leiter \& Maslach, 2009). Burnout is currently defined as a psychological response to 
chronic work stress that is typically characterised by feelings of exhaustion (Qiao \& Schaufeli, 2011).

\section{Measurement of burnout}

Whilst a large body of literature exists in relation to burnout, according to Sonnentag (2005), in the past few decades much of this literature has focused on the search for improved burnout measures. This is a necessary focus in burnout research since, although all the available burnout measures measure exhaustion, there are discrepancies in which dimensions it involves as well as the absence of a single measure that assesses all the important dimensions of burnout identified in the literature. The most commonly used measures within burnout research focus on the dimensions of exhaustion, cynicism, professional efficacy and disengagement from a general job perspective. These measures include the MBI general survey (Schaufeli, Leiter, Maslach \& Jackson, 1996), the burnout measure (MalachPines, 2005; Pines \& Aronson, 1988), the Shirom-Melamed burnout measure (Shirom, 1989, 2003), the Oldenburg burnout inventory (Demerouti, Bakker, Vardakou \& Kantas, 2003), and the Copenhagen burnout inventory (Kristensen, Borritz, Villadsen \& Christensen, 2005).

The Maslach burnout inventory: The MBI is the most widely used burnout measure. The various variations include the MBI human services survey (MBI-HSS), the MBI student survey (MBI-SS) and the MBI general survey (MBI-GS). The MBI-GS (Schaufeli et al., 1996) was initially developed for English-speaking populations (Demerouti et al., 2003). According to the developers, the MBI-GS can be used in any occupational context and includes three subscales: exhaustion, cynicism and professional efficacy (Schaufeli \& Enzmann, 1998). These three components are similar to those included in the original MBI, but consist of items that are not contextualised in human services work:

The emotional exhaustion subscale measures primarily depletion of physical energy and fatigue but does not refer to people as the source of these feelings. The cynicism subscale, which replaced the MBI depersonalization subscale, reflects indifference or a distant attitude toward one's work in general. Reduced personal efficacy or ineffectiveness, which is similar to the MBI's personal accomplishment subscale, refers to a decline in one's feelings of competence and successful achievement in one's work. (Shirom \& Melamed, 2006, p. 178)

One major limitation of the MBI-GS is that it does not measure all the dimensions of burnout. The MBI-GS focuses only on the affective component of emotional exhaustion (Halbesleben \& Demerouti, 2005). Several researchers (Pines, Aronson \& Kafry 1982; Shinn, 1982) have suggested that the exhaustion component should be expanded to include other aspects of exhaustion, including cognitive and physical exhaustion. Including these aspects would better capture the nature of exhaustion experienced as a result of chronic work stress. The scale also fails to measure cognitive impairment and distress syndrome. The MBI-GS therefore measures a narrow conceptualisation of the burnout construct, as does the MBI
(Schaufeli, 2003). The reduced personal accomplishment dimension has been found to be problematic and has the weakest empirical support of the three suggested burnout dimensions (Shirom, 2011). In fact, some researchers have suggested that professional efficacy should be regarded as a personality change and not as part of the burnout construct (Cordes \& Dougherty, 1993; Schaufeli, 2003).

In addition, as pointed out by Shirom and Melamed (2006), the three dimensions of the MBI (in all its versions) resulted from the labelling of exploratory factor-analysed items originally collected to show the range of experiences related to the burnout phenomenon rather than being theoretically deduced (Maslach, 1998; Schaufeli \& Enzmann, 1998). Furthermore, the third dimension of the MBI-GS (reduced efficacy) includes the concepts of incompetence, low self-efficacy, lack of productivity and lack of accomplishment (Leiter \& Maslach, 2001). According to Shirom and Melamed, these concepts are all distinct concepts within the behavioural sciences research field and should not be grouped together. Furthermore, the MBI-GS simply relabelled the MBI scale of depersonalisation as cynicism, whilst still implying the same types of symptoms; this represents a theoretical overlap with already defined measures of cynicism (Shirom \& Melamed, 2006).

Demerouti, Bakker, Nachreiner and Schaufeli (2001) highlight a further critical psychometric limitation of the MBI. Although all of the items of the three subscales are phrased in the same direction, the personal accomplishment scale is worded positively, whilst the exhaustion and depersonalisation scales are all worded negatively (Halbesleben \& Buckley, 2004). This could result in response bias and might have caused an artificial clustering of factors due to the positively and negatively worded scales (Bouman, Te Brake \& Hoogstraten, 2002).

Whilst recognising the role of interpersonal variables in the conceptualisation of the burnout construct, Maslach (1993) proposes that a multidimensional approach to burnout should be adopted and recommends that future studies should focus on the influence of individual factors. According to Maslach, new theoretical approaches needed to integrate all three dimensions (emotional exhaustion, depersonalisation and reduced personal accomplishment). However, research has found that when individuals report cases of burnout (in themselves or others), they often indicate the experience of exhaustion. Exhaustion is therefore the most commonly reported symptom of burnout and has also been extensively researched (Maslach et al., 2001).

The burnout measure: Researchers, such as Pines, Aronson and Kafry (1981), assume that burnout is a unidimensional construct exclusively reflecting exhaustion. Pines and her colleagues applied the term burnout to employment relationships (Pines et al., 1981) and organisational careers (Pines \& Aronson, 1988) as well as to marital relationships (Pines, 1996; Pines \& Aronson, 1988) and the aftermath of political conflicts (Pines, 1993). 
Pines and Aronson (1988) developed an instrument for the measurement of burnout that they named the burnout measure (BM). A recent short version (BMS) has been introduced (see Maslach-Pines, 2005). This instrument defines burnout as 'a state of physical, emotional and mental exhaustion caused by long-term involvement in emotionally demanding situations' (Pines \& Aronson, 1988, p. 9). Although the BM does distinguish between mental, emotional and physical exhaustion, an overall sum-score is used to assess burnout since this single score is easy to interpret (Pines, 1993). Studies on the factorial validity of the BM failed to distinguish more than one burnout (exhaustion) dimension (Corcoran, 1986; Schaufeli \& Van Dierendonck, 1993). Furthermore, studies have found that the physical and emotional aspects of exhaustion theorised by Pines et al. (1981) appear to collapse into one factor that reflects fatigue (Enzmann, Schaufeli, Janssen \& Rozeman, 1998). This is similar in terms of item content to the exhaustion subscale of the MBI. The results of the factor analysis of the BMS have shown inconsistent results in factor analysis across countries (see Malach-Pines, 2005).

The conceptualisation and measurement of burnout as exemplified by the BM became well established as a result of case studies and clinical experience (Shirom \& Melamed, 2005). In the course of developing the BM measure, Pines and her colleagues digressed from the initial way burnout was conceptualised towards an empirical description that views burnout 'as a syndrome of co-occurring symptoms including helplessness, hopelessness, entrapment, decreased enthusiasm, irritability, and a sense of lowered self-esteem' (Shirom \& Melamed, 2005, p. 603). Shirom and Melamed (2005) note that none of these symptoms is based in the work or job environment relationships.

Previous researchers such as Schaufeli and Van Dierendonck (1993) and Shirom and Ezrachi (2003) have described the BM as a general index of psychological distress that encompasses physical fatigue, emotional exhaustion, depression, anxiety and reduced self-esteem. The items of the BM are written in a general manner so that they can be used to assess any occupation. Although Enzmann et al. (1998) suggest that the measure should be seen as a useful diagnostic tool, other researchers have highlighted a number of problems with its factor structure and theoretical underpinnings (Enzmann et al., 1998; Schaufeli \& Van Dierendonck, 1993). Consequently, Shirom and Melamed (2006) recommend that the BM should not be used as a distinctive measure of burnout without significant modification and research attention.

The Shirom-Melamed burnout measure: The conservation of resources (COR) theory of Hobfoll and Freedy (1993) offers yet another conceptual approach to the burnout construct. According to Hobfoll and Freedy, stress occurs when work or other situations threaten an individual's ability to obtain or maintain resources. This approach therefore views burnout as relating principally to the physical, emotional and cognitive exhaustion experienced by an individual. The emphasis within the conceptual framework is the unremitting depletion of the individuals' energetic coping resources resulting from their chronic exposure to occupational stress (Shirom, 1989, 2003). According to COR theory, an individual has a basic motivation to obtain, retain and protect the resources that they value. Although these resources may include material, social and energetic resources, the concept of burnout in the Shirom-Melamed burnout measure (SMBM) relates only to energetic resources (Hobfoll \& Shirom, 1993, 2000; Shirom \& Melamed, 2005).

Shirom and his colleagues put forward three arguments for focusing solely on energetic resources in the construction of the SMBM. Firstly, these forms of energy are individually possessed and theoretically likely to be interrelated (Hobfoll \& Freedy, 1993). Furthermore, the COR theory proposes that personal resources not only influence each other, but also exist as a resource pool, such that a lack in one resource is often linked to a lack in another resource (Hobfoll \& Shirom, 2000). Secondly, these individually possessed forms of energy do not overlap with any other known behavioural science concept, such as cynicism and detachment, or facets of the self-concept such as self-esteem and self-efficacy. Thirdly, the burnout concept as measured by the SMBM clearly differentiates burnout from its antecedents, from coping behaviours and from likely consequences (Shirom \& Melamed, 2005).

The conceptualisation of burnout measured by the SMBM therefore consists of a combination of physical fatigue, emotional exhaustion and cognitive weariness (Shirom, 2003). Within this context, physical fatigue refers to feelings of tiredness and low levels of energy in carrying out daily tasks at work, such as getting up in the morning to go to work (Shirom \& Melamed, 2005). Emotional exhaustion refers to feeling too weak to display empathy towards clients or co-workers and lacking the energy needed to invest in relationships with other people at work. Finally, cognitive weariness refers to feelings of slow thinking and reduced mental agility (Shirom \& Melamed, 2005).

Therefore, based on SMBM's conceptualisation, burnout relates principally to energetic resources (Hobfoll \& Shirom, 1993, 2000) and excludes other resources (such as social resources) that could come into play in work settings. Although the conservation of resources theory is considered an individualistic approach, Hobfoll and Freedy (1993) state categorically that the system within which the individual functions should not be overlooked. In fact, Qiao and Schaufeli (2011) point out that by labelling the emotional exhaustion subscale of the SMBM as emotional or interpersonal exhaustion, Armon, Shirom, Shapira and Melamed (2008) tacitly acknowledge the fact that burnout does not result solely from an individual's energetic resource loss, but also from conditions such as interpersonal relationships at work. This interpersonal dimension of burnout has been referred to by Schaufeli (2003) as mental distance, which involves an individual's detached or insensitive attitude to their work, co-workers, patients or clients. 
The Oldenburg burnout inventory: The Oldenburg burnout inventory (OLBI) (Demerouti et al., 2003) is based on a similar model to the MBI and was developed in Germany. This scale was specifically designed to solve the potential wording bias of the MBI (Demerouti et al., 2003). The OLBI includes two scales (exhaustion and disengagement) that can be used to measure burnout in occupations both within and outside the human services professions (Demerouti, Bakker, Nachreiner \& Ebbinghaus, 2002).

One of the criticisms of the OLBI is that it uses both positively and negatively phrased items to measure exhaustion and disengagement. This could result in problems of interpretation because positive and negative affective states have been shown to have different antecedents (Baumeister, Bratslavsky, Finkenauer \& Vohs, 2001), may be examined independently (Davis, Zautra \& Smith, 2004) and are represented differently in people's behaviours (Gendolla, 2000) and physiological systems (Davidson, 2000; Wager, Phan, Liberzon \& Taylor, 2003).

The OLBI (in contrast to the MBI, which focuses only on affective components of emotional exhaustion) has items formulated to assess cognitive and physical components of exhaustion. This is in keeping with Shinn's (1982) previous suggestions in the burnout literature. Previous researchers (Demerouti et al., 2001) have confirmed the two-factor structure of the OLBI. However, in a study by Pretorius (2007), the OLBI presented item loadings that did not correspond with the originally intended factor structure reported by Demerouti et al. (2003). According to Pretorius, the OLBI does not deliver consistent results in terms of construct validity within the South African context. Brand (2006) also reported difficulties with the statistical analysis of the OLBI on a sample of 240 South African insurance employees. According to Brand, there is a serious question as to whether the items of the OLBI are properly phrased for use in South Africa. Pretorius recommends that more research be conducted on the use of the OLBI within the South African context. This research should focus either on developing an alternative measuring instrument or on adapting the current version.

The Copenhagen burnout inventory: Kristensen et al. (2005) developed the Copenhagen burnout inventory (CBI) in Denmark. The theoretical bases for the CBI are exhaustion and fatigue (Kristensen et al., 2005). A key feature of the CBI is that it differentiates between various domains of burnout (Kristensen et al., 2005). The instrument includes three subscales designed to measure three forms of burnout, which are defined in accordance with the life domain from which they arise. These three subscales are labelled as follows:

(1) personal or generic burnout, measuring the degree of physical and psychological exhaustion experienced by the person, regardless of occupational status, (2) work-related burnout, measuring the degree of physical and psychological exhaustion that is perceived by the person as related to work, and (3) client-related burnout, measuring the degree of physical and psychological exhaustion that is perceived by the person as related to work with clients. (Kristensen et al., 2005)

The instrument's developers suggest that a researcher should determine which scale to use based on the respondents to be assessed. This instrument is relatively new and therefore not many validation studies have been conducted.

The major limitation of the seven-item work-related burnout subscale of this instrument is that although the factor structure of the CBI items suggests that there are different dimensions in work-related burnout, these are not specified (Yeh, Cheng, Cheng, Hu \& Kristensen, 2007). However, according to Yeh et al. (2007), factor analysis of the CBI suggests that experiences of frustration at work or consequential aversion towards work might be a distinguishable form of workrelated burnout. The instrument's developers have yet to provide further psychometric support (for instance by using confirmatory factor analysis to test this assumption) for their claim that the three burnout scales are not totally dependent on each other.

In addition, a careful examination of the instrument prior to the start of the current research project suggested that the seven-item questionnaire would not be adequate for the purposes of this research. This study was designed to assess the physical, affective and cognitive components of burnout and the seven CBI items measured were considered not adequate to measure all three conceptualised dimensions, especially the cognitive dimension, of burnout.

\section{The present study}

Based on the above review of the literature, this study aimed to develop a comprehensive scale to measure burnout. The decision to develop a new instrument rather than adapting an existing one was firstly based on the fact that various limitations exist in each of the previously discussed instruments. Secondly, the information gathered from available literature suggested that burnout should be conceptualised as a multidimensional construct that consists of physical, emotional and cognitive components (Kahn, 1990; Pines \& Aronson, 1988; Schaufeli \& Greenglass, 2001; Shirom, 1989, 2003). Lastly, the developers of the instruments discussed above (MBI-GS, BM, OLBI, CBI and SMBM) all agree that exhaustion is part of the burnout experience. However, they differ in terms of the dimension of exhaustion that is measured. This study also aimed at exploring whether the burnout construct was basically related to fatigue and exhaustion or whether it includes other dimensions, such as aversion to work. Yeh et al. (2007) have proposed that other dimensions such as aversion to work could be embedded in the factor structure of the CBI and that it is closely related to what has been labelled mental distance or withdrawal (Schaufeli, 2003). This is also necessary considering the fact that the dimensions of burnout experienced by workers likely differ from one occupational group to another and between socio- 
economic groups (Yeh et al., 2007). Taking all these factors into account, developing a new, comprehensive instrument seemed to be an appropriate option.

Therefore, for the purposes of the current research project, burnout was viewed as a three-dimensional construct consisting of fatigue (physical component), cognitive weariness (cognitive component) and emotional exhaustion or withdrawal (emotional component). This is in keeping with definitions contained in the literature (e.g. Pines et al., 1981; Shirom, 1989; Shirom \& Melamed, 2005). Additionally, because the employees in organisations generally work in teams, emotional exhaustion includes measuring the effect of interpersonal relationships, considering the fact that Shirom and his colleagues (see Armon et al., 2008) have recently labelled emotional exhaustion as emotional or interpersonal exhaustion.

\section{Construct equivalence}

In developing a new instrument, the researchers were cognisant that this instrument should be suitable for use on a diverse range of individuals within the South African population. In this regard Rothmann (2003) notes that it is important to use a reliable and valid instrument to measure burnout, regardless of whether the assessment is being done for research purposes or for individual assessment. This is especially true within the multicultural South African context, where most organisations employ individuals with diverse cultural backgrounds. The Employment Equity Act, Section 8, stipulates that 'psychological testing and other similar assessments are prohibited unless the test or assessment being used (1) has been scientifically shown to be valid and reliable, (2) can be applied fairly to all employees, and (3) is not biased against any employee or group' (Republic of South Africa, 1998). South African researchers are therefore obligated to investigate, validate and standardise assessment tools so that they can be used within the multicultural South African context.

Test users and developers cannot merely assume that scores obtained in one culture within the South African setting can be compared across cultural groups. Before any comparisons are made between scores across cultural groups, equivalence and bias should be established (Van de Vijver \& Leung, 1997). This is necessary in order to ascertain the degree to which scores or constructs underlying an assessment tool can be compared across cultures. Bias denotes disparities in a measurement tool that do not have the same meaning within and across cultural groups (Poortinga, 1989). Bias is not intrinsic to a psychological measure, but instead results from the use of such a measure in two or more cultures (Van de Vijver \& Leung, 1997). In contrast, equivalence refers to the level of comparability of test scores and looks at whether or not scores obtained in different cultures can be meaningfully compared (Poortinga, 1989; Van de Vijver \& Leung, 1997). Bias and equivalence are interconnected: the presence of biased items in a measurement is usually a form of inequivalence.
Given that an individual's affiliation in terms of language and cultural groupings can impact the way in which that individual perceives the environment around them, Van de Vijver and Leung (1997) recommend assessing the construct equivalence and bias of instruments in multicultural research settings in order to account for these individual differences. Construct equivalence refers to the extent to which the same construct is measured across the cultural groups under study. Item bias concerns aspects of measurement validity in intercultural group comparisons (Van de Vijver \& Leung, 1997). It is therefore important to determine whether the newly developed burnout scale displays appropriate construct equivalence.

In light of the above, the following hypotheses were set for this study:

- Hypothesis 1: Burnout, as measured by the burnout scale, is a three-dimensional construct (consisting of fatigue, emotional exhaustion or withdrawal and cognitive weariness).

- Hypothesis 2: The burnout scale shows high internal consistency.

- Hypothesis 3a: Burnout is an equivalent construct for white and black employees.

- Hypothesis 3b: Burnout is an equivalent construct for African and Afrikaans language groups.

- Hypothesis 4: The burnout scale is unbiased for the Afrikaans, Sepedi and Sesotho language groups.

\section{Burnout in different demographic groups}

Whilst the focus of the study was validating a burnout scale on a sample of South African employees, the influence of demographic variables on burnout within the present sample could not be ignored. An emerging trend over the past decade has been the rapid growth in literature examining the interaction of key individual and environmental factors in developing burnout (Rothmann \& Barkhuizen, 2008), such as age, gender, race and employee rank.

According to Maslach et al. (2001), the demographic variable of age is consistently related to burnout, probably due to the relationship between age and work experience, thereby indicating that burnout seems to be more of a threat early in an individual's career. Other researchers (Jackson \& Rothmann, 2005; Kilfedder, Power \& Wells, 2001; Rothmann \& Barkhuizen, 2008) have found higher levels of burnout amongst younger employees when compared to their older colleagues.

Some researchers have hypothesised that women tend to experience more burnout compared to men (Maslach et al., 2001). Research findings have however been inconsistent, with some researchers reporting higher levels of burnout for women, whilst others report high levels of burnout for men and others report no gender differences (Maslach et al., 2001). There is a consistent finding that men score higher on cynicism, whilst their female counterparts score 
slightly higher on exhaustion, although this could easily be attributed to gender job stereotyping (Maslach et al., 2001). Whilst Rothmann and Barkhuizen (2008) found no significant differences between the burnout levels of gender groups, the follow-up analysis of variance showed that the levels of exhaustion, mental distance and professional efficacy did not differ between the gender groups.

With regard to employee rank, Barkhuizen and Rothmann (2008) and Jackson and Rothmann (2005) found no significant difference in levels of burnout based on rank. Finally, Coetzee and Rothmann (2004) found that white employees (in comparison to black employees) showed higher levels of exhaustion.

Despite all the studies done in other occupations showing that demographic variables could affect the burnout level of employees, there is no available literature on the effect of demographic variables on burnout of employees in the agricultural sector in South Africa.

In light of the above findings, the following additional hypothesis was set:

- Hypothesis 5: There is a significant difference in the burnout levels of participants based on different demographic variables.

\section{Research design}

\section{Research approach}

An exploratory research design approach was used to achieve the objectives of this research study as it is the ideal approach to use to examine the reliability, validity, construct equivalence and item bias of a newly developed burnout scale as well as to explore differences in the burnout levels of various demographic groups of workers in an agricultural research institution. For the purposes of the development of the burnout scale, a quantitative research methodology was employed. A cross-sectional field survey was used to gather the information required to achieve the research objectives. In cross-sectional surveys, several groups of participants are examined at one point in time (Salkind, 2009).

\section{Research method}

\section{Research participants}

The data was collected by means of convenience sampling. The research participants consisted of employees of a South African agricultural research institution. Although participation was voluntary, it was noted that employees from many of the job groups and educational levels in the organisation volunteered to partake in the study. However, the researcher took care to ensure that the participants with the lowest level of education had a literacy level sufficient for them to adequately complete the questionnaire. The biographical information for the study's participants is presented in Table 1.
TABLE 1: Biographical information of study participants $(N=443)$.

\begin{tabular}{|c|c|c|c|}
\hline Item & Category & Frequency & $\%$ \\
\hline \multirow[t]{3}{*}{ Gender } & Male & 221 & 49.9 \\
\hline & Female & 217 & 49.0 \\
\hline & Missing values & 5 & 1.1 \\
\hline \multirow[t]{5}{*}{ Race } & African & 247 & 55.8 \\
\hline & Mixed race & 19 & 4.3 \\
\hline & Indian & 3 & 7.0 \\
\hline & White & 170 & 38.4 \\
\hline & Missing values & 4 & 0.9 \\
\hline \multirow[t]{8}{*}{ Marital status } & Single & 124 & 28.0 \\
\hline & Engaged & 18 & 4.1 \\
\hline & Married & 232 & 52.4 \\
\hline & Living together & 16 & 3.6 \\
\hline & Separated/divorced & 24 & 5.4 \\
\hline & Widowed & 16 & 3.6 \\
\hline & Other & 5 & 1.1 \\
\hline & Missing values & 8 & 1.8 \\
\hline \multirow[t]{13}{*}{ Language } & Afrikaans & 165 & 37.2 \\
\hline & English & 21 & 4.7 \\
\hline & IsiNdebele & 5 & 1.1 \\
\hline & IsiXhosa & 6 & 1.4 \\
\hline & IsiZulu & 26 & 5.9 \\
\hline & Sepedi & 64 & 14.4 \\
\hline & Sesotho & 59 & 13.3 \\
\hline & Setswana & 38 & 8.6 \\
\hline & SiSwati & 14 & 3.2 \\
\hline & Tshivenda & 18 & 4.1 \\
\hline & Xitsonga & 8 & 1.8 \\
\hline & Other & 14 & 3.2 \\
\hline & Missing values & 5 & 1.1 \\
\hline \multirow[t]{9}{*}{ Age } & $20-25$ & 28 & 6.3 \\
\hline & $26-30$ & 53 & 12.0 \\
\hline & $31-35$ & 73 & 16.5 \\
\hline & $36-40$ & 60 & 13.5 \\
\hline & $41-45$ & 72 & 16.3 \\
\hline & $46-50$ & 71 & 16.0 \\
\hline & $51-55$ & 37 & 8.4 \\
\hline & $55+$ & 44 & 9.9 \\
\hline & Missing values & 5 & 1.1 \\
\hline \multirow[t]{9}{*}{ Education } & Grade $9-11$ & 59 & 13.3 \\
\hline & Grade 12 & 60 & 13.5 \\
\hline & Certificate/diploma & 70 & 15.8 \\
\hline & Bachelor's degree & 44 & 9.9 \\
\hline & Honours degree & 42 & 9.5 \\
\hline & Master's degree & 86 & 19.4 \\
\hline & $\mathrm{PhD}$ & 51 & 11.5 \\
\hline & Other & 24 & 5.4 \\
\hline & Missing values & 7 & 1.6 \\
\hline \multirow[t]{6}{*}{ Position } & Research assistant & 124 & 28.0 \\
\hline & Research technician & 122 & 27.5 \\
\hline & Researcher & 110 & 24.8 \\
\hline & Programme manager/specialist scientist & 17 & 3.8 \\
\hline & Support staff & 62 & 14.0 \\
\hline & Missing values & 8 & 1.8 \\
\hline
\end{tabular}

A summary of the demographic details of the participants indicates that $49.9 \%$ of the participants were men and that $55.8 \%$ of the participants belonged to the African racial group. Married individuals comprised $52.4 \%$ of the sample. Furthermore, $37.2 \%$ of the participants belonged to the Afrikaans-speaking group and $16.5 \%$ of the participants were between 31 and 35 years of age. Approximately one-fifth 
(19.4\%) of the participants have master's degrees; research assistants had the highest percentage (28.0\%) representation; $44.0 \%$ of the participants had been in their positions for between one and five years, whilst $34.3 \%$ of the participants had been employed in the research institution for between one and five years.

\section{Measuring instruments}

A self-developed burnout scale was used to measure the burnout of employees within the agricultural sector. The initial scale consisted of 20 items specially designed to measure the fatigue (six items, e.g. 'I feel weak while at work'), emotional exhaustion or withdrawal (seven items, e.g. 'I am not affected by how other people at work feel') and cognitive weariness (seven items, e.g. 'I can't think clearly while at work') of burnout. The items were scored on a seven-point frequency scale ranging from 1 (never) to 7 (always). Foddy (1994, as cited by Pearse, 2011) recommends that a minimum of seven categories is required to ensure scale validity and reliability.

\section{The development of the burnout scale}

A thorough study of the available literature on burnout was conducted in order to develop a scale to measure burnout amongst employees in the agricultural sector. The information gathered from available literature suggested that burnout should be conceptualised as consisting of physical, emotional (relational) and cognitive components. Based on the literature, items were written to assess each of these components. For example, the item 'I feel weak while at work' was developed for the physical component. Once the items were developed, they were sent to three industrial psychologists as experts for review. The reviewers checked for the following: (1) ambiguity of words used to construct the items in order to ensure better understanding of the items, (2) double-barrelled questions to ensure that there was only one indicator in each item, (3) use of contractions such as don't instead of do not and (4) use of frequency indicators (e.g. sometimes) already included in the Likert scale.

A pilot survey was conducted with 50 employees from the same research institution in which the survey was to be conducted. These employees were from the same job groups and educational level as those employees to be included in the final survey. The purpose of the pilot survey was to evaluate the item content to determine which items the respondents found difficult to understand and to determine whether the instructions were clearly understood by the respondents. The respondents reported no difficulties in understanding the content of the items and instructions.

\section{Research procedure}

A South African agricultural research institution was approached to be part of the study and once written permission from the director of human resources of the institution was received the project commenced. A letter explaining the objective of the survey and requesting participation in the survey was then emailed to employees within the research institution. Questionnaires were personally distributed by hand by the researcher to 511 participants who indicated their willingness to participate in this study. The questionnaires were collected by the researcher following a 6-week period. A total of 472 questionnaires were returned, representing a $92 \%$ response rate. However, 29 of the 472 questionnaires collected were improperly completed and were therefore unusable for data analysis.

The ethical considerations that were appropriate for this study included voluntary participation, informed consent and confidentiality. Voluntary participation means that no participant was coerced into completing the questionnaire, whilst the prospective research participants were also fully informed about the procedures and risks involved in research and gave their consent to participate (cf. Trochim, 2006). Lastly, the participants were assured that identifying information would not be made available to anyone who is not directly involved in the study (cf. Trochim, 2006).

\section{Statistical analysis}

The statistical analysis was carried out using the SPSS software (SPSS Statistics for Windows, 2012). In the first step, means, standard deviations, skewness and kurtosis were determined to describe the data. A cut-off point of 2.00 was set for skewness and 4.00 for kurtosis to ensure that the data was normally distributed. The reliability and validity of the burnout scale were also determined by means of Cronbach's alpha coefficients, as well as exploratory factor analysis. Nunnally and Bernstein (1994) recommend a 0.70 as an acceptable guideline for determining the internal consistency of an instrument. It is important for a measuring instrument to have an acceptable alpha coefficient, as this is crucial to make decisions as to whether the items measure a similar construct.

A simple principal components analysis was first conducted on the items of the burnout scale for the total sample. The eigenvalues, scree plot and parallel analysis were studied to determine the number of factors. Subsequently, a direct Oblimin rotation was used to determine the solution for the total sample. Factors were retained based on the following criteria: (1) the item loadings were above 0.32 , (2) the items loaded on only one factor, indicating that there is no overlap of factors or components, (3) each factor had at least three substantive item loadings and (4) the retained factor was theoretically meaningful (see Clark \& Watson, 1995; Field, 2005; Pallant, 2010). The reliability for the total sample was determined by Cronbach's alpha coefficients.

Construct equivalence was examined for language and racial groups. A simple principal component analysis with a direct Oblimin rotation was then computed for each language and racial group. The same criteria used to retain factors for the total sample were applied for the racial and language groups. Based on the composition of the sample, it was decided to conduct the analysis for construct equivalence on race groups 
and on the Afrikaans and African languages rather than on all the different language groups in the sample. Although the best approach would have been to compare the African languages separately, the sample sizes of the language groups were not sufficiently large to satisfy the assumptions of the statistical techniques that were employed. However, evaluating the construct equivalence of both racial and linguistic groups and item bias for the Afrikaans, Sepedi and Sesotho language groups offered some level of cultural comparison in relation to both racial and linguistic groupings.

'Construct equivalence can be investigated with several techniques, such as factor analysis, cluster analysis and multidimensional scaling or other dimensionality-reducing techniques (Van de Vijver \& Leung, 1997). The central idea behind the application of these techniques is to obtain a structure for each culture, which can then be compared across all cultures involved. Factor analysis is the most frequently employed technique to study construct equivalence; this study therefore made use of exploratory factor analysis to examine construct equivalence. A principal component analysis with a direct Oblimin rotation was used to determine the solution for each cultural (linguistic and racial) group. Factors obtained (after factor analysis) in each racial and linguistic group were compared (after target rotation).

According to Van de Vijver and Leung (1997), the comparison between the similarities of the factor structure of two cultural groups could be underestimated as a result of the arbitrary spatial distribution of factors through factor analysis. It is therefore suggested that target rotation be conducted prior to comparing the factor solutions of cultural groups by rotating the factor loading matrices with regard to each other in order to significantly improve the agreement between the factors. Whilst carrying out this procedure, one group is arbitrarily assigned to be the target group and the factor loadings of the other group are rotated towards the target group to form a common factor matrix. In this study, the agreement was evaluated through the use of a factor congruence coefficient, Tucker's phi (Van de Vijver \& Leung, 1997). According to this statistic, values above 0.90 are taken to point to essential agreement between cultural groups, whilst values above 0.95 point to very good agreement.

The items were tested for differential item functioning (item bias) using conditional analysis of variance (ANOVA), which is an application of Cleary and Hilton's (1968) ANOVA (Matsumoto \& Van de Vijver, 2011; Van de Vijver \& Leung, 1997). Although different statistical methods are available to analyse item bias, ANOVA was used in this study because of its inherent advantages. These advantages include computational ease, robustness and the possibility of studying both uniform and non-uniform bias (Mellenbergh, 1982). The comparison was made between the three language groups that had the highest number of participants (i.e. Afrikaans, Sepedi and Sesotho). Each item was examined for bias separately. The language groups (three levels) and score levels were the independent variables, whilst the score for the item was the dependent variable.
Score levels were calculated using the total score on the burnout scale. According to Van de Vijver and Leung (1997), when determining score groups, minimum and maximum score groups should not be considered because the responses of all the respondents would essentially be alike throughout the groups, thereby making it 'impossible' to study bias. Score levels were calculated using the total score on the burnout scale whilst excluding all minimum and maximum obtainable scores. A total of four levels were attained by making use of percentiles identified through SPSS. Using this method made it possible to use score groups with at least 50 people in each group (Van de Vijver \& Leung, 1997). Two effects were tested: (1) the main effect of language and (2) the interaction of score level and language. When the main effect of language was significant, the item was taken to have uniform bias. When the interaction of score level and culture was significant, the item was taken to have non-uniform bias. Pallant (2010) recommends that when the assumption of equality of error variances is violated in ANOVA univariate analysis (with two independent variables), the significance level should be set to 0.01 . When any item is statistically significant for uniform or non-uniform bias, the effect size is examined to determine whether or not the obtained results are of practical importance. A cut-off point of 0.50 (medium effect) was set for practical significance in this research (Cohen, 1988).

Multivariate analysis of variance (MANOVA) was used to determine the significance of differences between the burnout of demographic groups. MANOVA tests whether mean differences amongst groups on a combination of dependent variables are likely to have occurred by chance (Tabachnick \& Fidell, 2001). In MANOVA, a new dependent variable that maximises group differences is created from the set of dependent variables. Wilks's lambda is used to test the 'likelihood of the data under the assumption of equal population mean vectors for all groups against the likelihood under the assumption that the population mean vectors are identical to those of the sample mean vectors for the different groups' (Tabachnick \& Fidell, 2001, p. 348). When an effect is significant in MANOVA, one-way ANOVA is used to discover which dependent variables have been influenced. Because multiple ANOVAs were used, a Bonferoni-type adjustment was used to control for inflated Type I error. Games-Howell tests were also conducted to indicate which group differed significantly when ANOVAs were conducted. According to Cohen (1988), when determining statistical significance, values between 0.10 and 0.50 indicate a small effect, values between 0.50 and 0.80 indicate a medium effect and values over 0.80 indicate a large effect. In terms of the current research, a cut-off point of 0.50 (medium effect) was set for the practical significance of the differences between group means.

\section{Results}

The first step in the data analysis involved examining the descriptive statistics of the initial 20 items of the burnout scale. The results indicated that none of the items had kurtosis that exceeded 4.00 or skewness that exceeded 2.00. 
This implies that none of the items deviated from the normal distribution, which would have indicated the presence of clustering of scores.

All 20 items of the burnout scale were therefore used as input for principal component analysis to determine the number of components that could be extracted. The eigenvalues indicated that three factors that explained $58.55 \%$ of the variance could be extracted from the burnout scale. The scree plot was then inspected and is presented in Figure 1.

Figure 1 shows a break between the third and fourth component, indicating that three factors could be extracted.

Parallel analysis was also conducted to compare the eigenvalues obtained from the principal component analysis with those of a randomly generated dataset of the same kind. The results of this analysis also indicated that three factors could be extracted when the initial eigenvalue from the SPSS

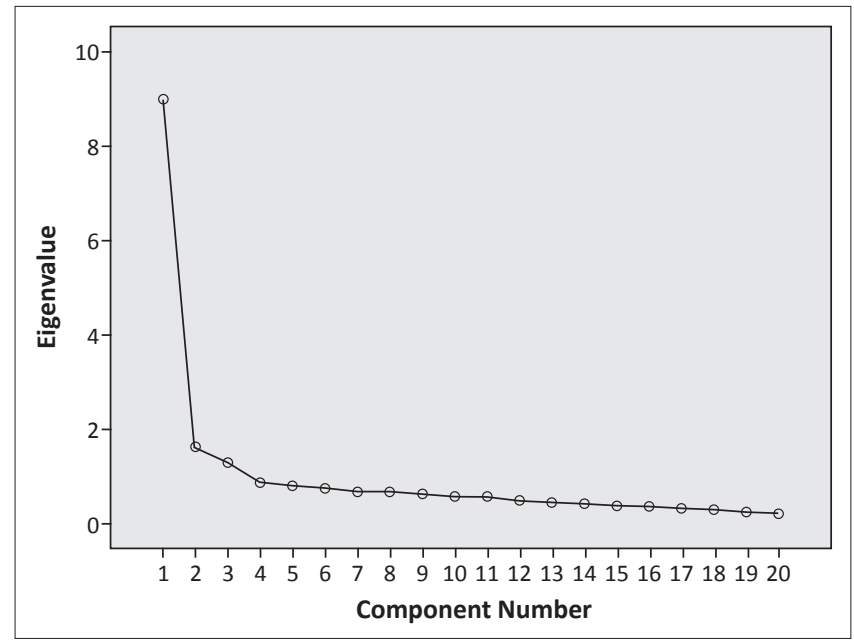

FIGURE 1: Scree plot of the burnout scale items. analysis (1.30) was compared to the random eigenvalue from the parallel analysis (1.27). Taking all three indicators into account, three factors were therefore extracted from the data.

A principal component analysis with a direct Oblimin rotation was then conducted on the total sample and is presented next in Table 2.

Table 2 shows that three items (items BS_6, BS_10, and BS_17) proved problematic as they cross-loaded onto two factors. These items were subsequently excluded from further analysis.

The factor loadings following the deletion of the three crossloaded items are shown in Table 3.

Table 3 shows that three factors, labelled cognitive weariness (Factor 1), fatigue (Factor 2) and emotional exhaustion or withdrawal (Factor 3), could be extracted. This supports hypothesis 1 and suggests that burnout consists of three factors. The communalities of the obtained three factors ranged between 0.46 and 0.71 .

Next, in Table 4, descriptive statistics, reliability and Pearson's correlation of the factors are presented.

Table 4 shows that the three burnout scale factors are normally distributed. It also indicates that all three of the obtained factors from the burnout scale are reliable using the guideline of alpha values over 0.70 , as suggested by Nunnally and Bernstein (1994). The Cronbach's alpha results for the three factors ranged between 0.82 , and 0.88 . The results further provide support for hypothesis 2, indicating that the measuring instrument shows high internal consistency. The results also show that fatigue correlated practically and significantly with cognitive weariness $(r=0.56$, large effect) and emotional exhaustion or withdrawal ( $r=0.49$, large effect), whilst emotional exhaustion

TABLE 2: Factor loadings of the initial 20-item burnout scale items $(N=443)$.

\begin{tabular}{|c|c|c|c|c|}
\hline Item number & Item & Factor 1 & Factor 2 & Factor 3 \\
\hline BS_1 & I feel weak while at work. & -0.02 & 0.75 & 0.05 \\
\hline BS_2 & I do not have enough energy to carry out my daily tasks. & 0.11 & 0.71 & 0.08 \\
\hline BS_3 & I do not have the energy to go to work in the morning. & 0.08 & 0.73 & 0.04 \\
\hline BS_4 & I feel exhausted at the end of a working day. & 0.04 & 0.72 & -0.04 \\
\hline BS_5 & I feel emotionally exhausted at work. & 0.10 & 0.76 & -0.03 \\
\hline BS_6 & My work makes me feel weary. & 0.13 & $0.43^{*}$ & $0.35^{*}$ \\
\hline BS_7 & I do not feel like building relationships with my co-workers. & 0.00 & -0.04 & 0.84 \\
\hline BS_8 & I lack the energy to build relationships with people at work. & 0.07 & 0.05 & 0.73 \\
\hline BS_9 & I feel I am less connected to my work. & -0.03 & 0.13 & 0.69 \\
\hline BS_10 & I feel frustrated at work. & -0.13 & $0.37 *$ & $0.56^{*}$ \\
\hline BS_11 & I am unable to imagine the feelings of my co-workers. & 0.16 & 0.08 & 0.54 \\
\hline BS_12 & I am not emotionally affected by how other people at work feel. & -0.03 & -0.02 & 0.66 \\
\hline BS_13 & I am not excited about my job. & 0.23 & -0.23 & 0.62 \\
\hline BS_14 & I do not think clearly while at work. & 0.65 & 0.22 & 0.08 \\
\hline BS_16 & I struggle to process problems quickly. & 0.67 & 0.07 & 0.07 \\
\hline BS_17 & The thought of the work I have to do make me tired. & $0.50 *$ & $0.34 *$ & 0.12 \\
\hline BS_18 & I find it difficult to learn new things on my job. & 0.81 & -0.13 & 0.07 \\
\hline BS_19 & I find it difficult to think about complex things while at work. & 0.89 & -0.08 & -0.05 \\
\hline BS_20 & I am not focused while working. & 0.65 & 0.20 & -0.02 \\
\hline
\end{tabular}

*, Indicates items that loaded on more than one factor. 
or withdrawal was significantly and practically related to cognitive weariness $(r=0.63$, large effect).

Following the deletion of the three cross-loaded items, a principal component analysis with a direct Oblimin rotation was again conducted on the different racial and language groups. Thereafter, the obtained pattern matrices were used as input for target rotation. Three factors, labelled cognitive weariness, fatigue and emotional exhaustion or withdrawal, with acceptable Tucker's phi coefficients (> 0.90), were obtained from white and black employees, as well as from the African and Afrikaans language groups. The Tucker's phi value for cognitive weariness was 0.94 in both instances, which suggests essential agreement between the respective racial groups on the one hand and the two language groups on the other (cf. Van de Vijver \& Leung, 1997). Fatigue and emotional exhaustion or withdrawal had Tucker's phi values of over 0.95 , indicating again very good agreement firstly between the respective racial groups and secondly between the language groups (cf. Van de Vijver \& Leung, 1997). These results indicate that the same construct of burnout was measured in the two racial groups (confirming hypothesis 3a) and the two language groups (confirming hypothesis $3 \mathrm{~b}$ ).

TABLE 3: Pattern matrix of the 17-item burnout scale for the total sample.

\begin{tabular}{|c|c|c|c|}
\hline $\begin{array}{l}\text { Item } \\
\text { number }\end{array}$ & Item & Factor & $h^{2}$ \\
\hline \multicolumn{4}{|c|}{ Factor 1: Cognitive weariness } \\
\hline BS_14 & - I do not think clearly while at work. & 0.66 & 0.69 \\
\hline BS_15 & - I cannot concentrate while at work. & 0.72 & 0.71 \\
\hline BS_16 & - I struggle to process problems quickly. & 0.69 & 0.57 \\
\hline BS_18 & $\begin{array}{l}\text { - I find it difficult to learn new things on } \\
\text { my job. }\end{array}$ & 0.78 & 0.63 \\
\hline BS_19 & $\begin{array}{l}\text { - I find it difficult to think about complex } \\
\text { things while at work. }\end{array}$ & 0.89 & 0.70 \\
\hline BS_20 & - I am not focused while working. & 0.67 & 0.57 \\
\hline \multicolumn{4}{|c|}{ Factor 2: Fatigue } \\
\hline BS_1 & - I feel weak while at work. & 0.77 & 0.61 \\
\hline BS_2 & $\begin{array}{l}\text { - I do not have enough energy to carry out } \\
\text { my daily tasks. }\end{array}$ & 0.71 & 0.65 \\
\hline BS_3 & $\begin{array}{l}\text { - I do not have the energy to go to work in } \\
\text { the morning. }\end{array}$ & 0.75 & 0.64 \\
\hline BS_4 & $\begin{array}{l}\text { - I feel exhausted at the end of a working } \\
\text { day. }\end{array}$ & 0.72 & 0.52 \\
\hline BS_5 & - I feel emotionally exhausted at work. & 0.77 & 0.65 \\
\hline \multicolumn{4}{|c|}{ Factor 3: Emotional exhaustion or withdrawal } \\
\hline BS_7 & $\begin{array}{l}\text { - I do not feel like building relationships } \\
\text { with my co-workers. }\end{array}$ & 0.79 & 0.65 \\
\hline BS_8 & $\begin{array}{l}\text { - I lack the energy to build relationships } \\
\text { with people at work. }\end{array}$ & 0.75 & 0.65 \\
\hline BS_9 & - I feel I am less connected to my work. & 0.66 & 0.53 \\
\hline BS_11 & $\begin{array}{l}\text { - I am unable to imagine the feelings of my } \\
\text { co-workers. }\end{array}$ & 0.52 & 0.46 \\
\hline BS_12 & $\begin{array}{l}\text { - I am not emotionally affected by how } \\
\text { other people at work feel. }\end{array}$ & 0.72 & 0.46 \\
\hline BS_13 & - I am not excited about my job. & 0.66 & 0.50 \\
\hline
\end{tabular}

The differential item functioning statistic (DIF) was computed for Afrikaans, Sepedi and Sesotho participants and none of the items for cognitive weariness, fatigue and emotional exhaustion or withdrawal tested significant for both uniform and non-uniform bias. This lends support to hypothesis 4, which suggests that the burnout scale is not biased against any of the Afrikaans, Sepedi or Sesotho language groups.

Preliminary assumption checking was conducted to check for normality, linearity, univariate and multivariate outliers, homogeneity of variance-covariance matrices and multicollinearity. As no serious violations were noted with regard to these criteria, MANOVA was then used to determine differences between demographic groups in terms of job demands and resources. The demographic groups included were gender, race, marital status, age, education, years in research institution and years in position. An analysis of Wilks's lambda values suggested the existence of statistically significant differences for age $(F=2.50, p=0.000)$, education $(F=2.03, p=0.005)$ and years in position $(F=1.82$, $p=0.023)$. However, when the results for the dependent variables were examined separately using a Bonferroni adjusted level of 0.017 , only one dependent variable for age (fatigue, F2) recorded a significance value less than the cut-off $(F=2.65, p=0.014)$. This shows that there was a statistically significant difference in burnout in relation to the age of the employees, but no statistically significant differences in relation to marital status, education and years in position. Hypothesis 5 was therefore partially accepted.

An ANOVA was then performed to further investigate the relationship between the dependent variable (fatigue) and the age of the employees as measured by the burnout scale. Participants were divided into eight groups according to their age (20-25, 26-30, 31-35, 36-40, 41-45, 46-50, 51-55 and $55+)$. There was a statistically significant difference at the $p$ greater than 0.05 level in fatigue scores for the groups based on age $(F(2.478)=4.4, p=0.019)$. However, despite the fact that it was statistically significant, the actual difference in mean scores between the groups was relatively small. The effect size calculated using Eta squared was 0.03. Post-hoc comparisons using Games-Howell indicated that the mean score for employees within the 20-25 group $(M=11.32$, $\mathrm{SD}=3.32)$ was significantly lower than those for the 31-35 $(\mathrm{M}=13.81, \mathrm{SD}=4.11), 36-40(\mathrm{M}=14.32, \mathrm{SD}=5.32)$ and $46-50$ $(\mathrm{M}=14.66, \mathrm{SD}=5.41)$ age groups.

\section{Discussion}

The main objectives of this research study were to (1) give an overview of the current burnout measures being used in the

TABLE 4: Descriptive statistics, reliability and Pearson correlation coefficient of the factors.

\begin{tabular}{lllllll}
\hline Factor & Mean & SD & Skewness & Kurtosis & $\boldsymbol{\alpha}$ & $\mathbf{1}$ \\
\hline 1. Cognitive weariness & 12.40 & 5.56 & 0.79 & -0.03 & 0.88 & 1 \\
2. Fatigue & 13.54 & 5.04 & 0.27 & -0.35 & 0.85 & $0.56 *$ \\
3. Emotional exhaustion or withdrawal & 14.02 & 5.54 & 0.57 & -0.35 & 0.82 & $0.63 *$ \\
\hline
\end{tabular}

*, Correlation is significant at the 0.01 level (two-tailed).

SD, standard deviation. 
literature, (2) identify potential gaps within these measures, (3) address these gaps through the development of a new burnout scale, (4) investigate the psychometric properties of the burnout scale on a South African sample of employees, (5) examine the construct equivalence of the newly developed measure for use on a diverse range of employees within South Africa and (6) explore whether demographic variables influenced the degree of burnout within South African employees.

The findings of the study confirmed the three-factor model of burnout, the three factors being cognitive weariness, fatigue and emotional exhaustion or withdrawal. The findings are similar to some found using existing burnout measures. With regard to the first factor, labelled fatigue, Enzmann et al. (1998) obtained a similar factor from the burnout measure, which they also labelled fatigue. This factor obtained by Enzmann et al. also comprised physical and emotional aspects of burnout as found in this study. Furthermore, fatigue is closely related to the exhaustion subscale of the MBI-GS (Schaufeli et al., 1996) and the OLBI (Demerouti et al., 2003). The exhaustion subscale of the MBI-GS consists of items that primarily relate to the affective component of exhaustion, whilst that of the burnout scale includes physical tiredness. On the other hand, the OLBI exhaustion subscale measures physical, emotional and cognitive exhaustion.

The second factor, labelled emotional exhaustion or withdrawal, found in the current study included items that not only combine the emotional exhaustion component as proposed in SMBM, but also measure interpersonal aspects of exhaustion, whereas the SMBM items assess only the depletion of the individual's affective energetic reaction to chronic work stress (Qiao \& Schaufeli, 2011). Furthermore, the emotional exhaustion or withdrawal dimension includes the employees' detached attitude to work, whilst the MBI-GS cynicism scale measures only the employees' detached attitude to work.

The cognitive weariness subscale measures a state of slow thinking and reduced mental agility as conceptualised by the SMBM (Shirom \& Melamed, 2005). Although Pines and Aronson (1988) and Shirom and Melamed (2005) theorised this in the BM and SMBM respectively, they did not obtain a separate factor measuring cognitive weariness. All three of these subscales proved to be highly reliable.

The current study's finding regarding the construct equivalence of burnout (as measured by the Burnout scale) for racial groups is in keeping with the findings reported by Storm and Rothmann (2003), who found construct equivalence for the MBI-GS for white and black employees. It can be deduced that the same construct of burnout can be measured in the two groups (Van der Vijver \& Leung, 1997). Construct equivalence was also found for the three dimensions of the burnout scale (cognitive weariness, fatigue and emotional exhaustion or withdrawal) for the Afrikaans and African language groups. Jackson and Rothmann (2005) also found equivalence in the burnout construct during their study of the adaptation of MBI-GS for Afrikaans-speaking and African language-speaking educators. However, Jackson and Rothmann's assessment of burnout was based on an adapted model of the MBI-GS that consisted of exhaustion, cynicism or depersonalisation (which merged into mental distancing) and professional efficacy.

Differential item functioning (item bias) was investigated for the Afrikaans, Sepedi and Sesotho groups and the results indicated that no items had uniform or non-uniform bias. The burnout scale therefore meets the stipulation that any instrument that is to be used in a multicultural setting with diverse linguistic and racial groups should not contain items that are biased against cultural groups (Van der Vijver \& Leung, 1997; Van der Vijver \& Rothmann, 2004).

Differences in the fatigue levels of employees from different age groups were found in that employees who were between the ages of 20 and 25 scored significantly lower than those who were aged between 31 and 50. This finding is in contrast with findings in previous studies. Jackson and Rothmann (2005) found that employees between 45 and 50 years of age experienced lower scores than younger employees (aged below 27 years of age). In this study, it was hypothesised that the lower fatigue levels of employees aged between 20 and 25 years of age could be accounted for by the fact that workers tend to take on greater family responsibilities and work overload as they age (Osipow, Doty \& Spokane, 1985). This finding is also supported by the finding of Ekstedt et al. (2006), who found that fatigue in occupational burnout may be attributed to variables external to the work environment such as disturbed sleep.

\section{Limitations}

A limitation of this study is the composition of the sample in terms of cultural groups, which made it impossible to examine construct equivalence for mixed race and Indian employees as well. In addition, the language grouping could also have been used to test for construct equivalence had the sample been large enough to justify the statistical method used. Another limitation is the use of self-report measures. The use of self-report measures is known to result in common method variance problems, although researchers are yet to agree fully on whether or not this poses problems for research (Spector, 2006; Tremblay \& Messervey, 2011).

\section{Recommendations}

Based on the findings of this study, it is recommended that the burnout scale be used to assess the burnout levels of employees in agricultural research institutions in South Africa. Although evidence was found for the validity and reliability of the burnout scale in this study, it is also recommended that further research be undertaken to assess the validity and reliability of the burnout scale in other sectors and research institutions in South Africa. Additionally, confirmatory factor analysis using structural equation modelling could be used to investigate 
the factor structure of the burnout scale. Further studies should also test the construct equivalence of the instrument for the various cultural groups. It is also recommended that longitudinal research studies that allow inferences regarding cause and effect with regard to the burnout construct be carried out in future research. Future studies could also be done using a stratified random sample design in which the researcher would pre-organise the sampling frame into various groups according to levels of the variables that could be important to the research. Using this sampling method would ensure maximising the probability that all cultural groups are adequately represented in the research sample. Lastly, it is also recommended to investigate the differences between groups in the experience of burnout using the burnout scale.

\section{Conclusion}

The findings of this study provide information regarding the burnout levels of employees in an agricultural research institution (based on different demographics). These findings could serve as a reference for both practitioners and researchers to plan interventions. The evidence provided in this research with regard to the validity and reliability of the burnout scale suggests that the burnout scale could be used to reliably assess burnout within the agricultural research sector. Likewise, the burnout scale could be used to measure the level of burnout of other knowledge workers, specialists and workers working within similar research institutions for whom the general aim is to conduct research, drive research and development, drive technology development and disseminate information. The items in the burnout scale are not sector specific and therefore should have more generalisability to other organisations.

The development of this instrument therefore opens up a range of possibilities concerning burnout research in South Africa and beyond as it provides researchers with an instrument that could be used to measure the relationship between the three subcomponents of burnout (cognitive weariness, fatigue and emotional exhaustion or withdrawal) and other psychological variables.

\section{Acknowledgements}

The financial assistance of the National Research Foundation (grant number 76306) towards this research is acknowledged. The opinions expressed and conclusions arrived at in this article are those of the authors and should not be attributed to the National Research Foundation.

\section{Competing interests}

The authors declare that they have no financial or personal relationship(s) that may have inappropriately influenced them in writing this article.

\section{Authors' contributions}

D.N.A. (North-West University) was lead author, wrote up the article and was responsible for data collection and part of the data analysis. L.I.J. (North-West University) was the postgraduate supervisor of the lead author, secondary writer of the literature review and gave editorial input. C.H. (University of Johannesburg) was associate supervisor of the lead author, secondary writer of the literature review and assisted in the data analysis.

\section{References}

Ahola, K., Toppinen-Tanner, S., Huuhtanen, P., Koskinen, A., \& Väänänen, A. (2009). Occupational burnout and chronic work disability: An eight-year cohort study on pensioning among Finnish forest industry workers. Journal of Affective Disorders, 115(1), 150-159. http://dx.doi.org/10.1016/j.jad.2008.09.021

Armon, G., Shirom, A., Shapira, I., \& Melamed, S. (2008). On the nature of burnout-insomnia relationships: A prospective study of employed adults. Journal of Psychosomatic Research, 65, 1-5. http://dx.doi.org/10.1016/ j.jpsychores.2008.01.012

Baumeister, R.F., Bratslavsky, E., Finkenauer, C., \& Vohs, K.D. (2001). Bad is stronger than good. Review of General Psychology, 5, 323-370.

Bekker, M.H., Croon, M.A., \& Bressers, B. (2005). Childcare involvement, job characteristics, gender and work attitudes as predictors of emotional exhaustion and sickness absence. Work \& Stress, 19(3), 221-237. http://dx.doi. org/10.1080/02678370500286095

Bouman, A.M., Te Brake, H.T., \& Hoogstraten, J. (2002). Significant effects due to rephrasing the Maslach burnout inventory's personal accomplishment items. Psychological Reports, 91(3), 825-826. http://dx.doi.org/10.2466/ pr0.2002.91.3.825

Brand, L. (2006). Burnout, work engagement and workaholism among employees in the insurance industry Master's dissertation, School for Human Resource Sciences, North-West University, Potchefstroom, South Africa.

Clark, L.A., \& Watson, D. (1995). Construct validity: Basic issues in objective scale development. Psychological Measurement, 28, 61-75. http://dx.doi. org10.1037//1040-3590.7.3.309

Cleary, T., \& Hilton, T.L. (1968). An investigation of item bias. Educational and Psychological Measurement, 28, 61-75. http://dx.doi. org/10.1177/001316446802800106

Coetzee, S.E., \& Rothmann, S. (2004). An adapted model of burnout for employees at a higher education institution in South Africa. South African Journal of Industrial Psychology, 30(3), 29-40.

Cohen, J. (1988). Statistical power analysis for the behavioral sciences. (2nd edn.). Orlando, CA: Academic Press.

Corcoran, K.J. (1986). Measuring burnout: A reliability and convergent validity study. Journal of Social Behavior and Personality, 1, 107-112.

Cordes, C.L., \& Dougherty, T.W. (1993). A review and an integration of research on job burnout. Academy of Management Review, 18(4), 621-656.

Cox, T., Tisserand, M., \& Taris, T. (2005). The conceptualization and measurement of burnout: Questions and directions. Work \& Stress, 19(3), 187-191. http:// dx.doi.org/10.1080/02678370500387109

Demerouti, E., Bakker, A., Nachreiner, F., \& Ebbinghaus, M. (2002). From mental strain to burnout. European Journal of Work and Organizational Psychology, 11(4), 423-441. http://dx.doi.org/10.1080/13594320244000274

Davidson, R.J. (2000). Affective style, psychopathology, and resilience: Brain mechanisms and plasticity. American Psychologist, 55, 1196-1214.

Davis, M.C., Zautra, A.J., \& Smith, B.W. (2004). Chronic pain, stress, and the dynamics of affective differentiation. Journal of Personality, 72, 1133-1160

Demerouti, E., Bakker, A.B., Nachreiner, F., \& Schaufeli, W.B. (2001). The job demands resources model of burnout. Journal of Applied Psychology, 86, 499512. http://dx.doi.org/10.1037/0021-9010.86.3.499

Demerouti, E., Bakker, A.B., Vardakou, I., \& Kantas, A. (2003). The convergent validity of two burnout instruments: A multitrait-multimethod analysis. European Journal of Psychological Assessment, 19, 12-23. http://dx.doi.org/10.1027/ 1015-5759.19.1.12

Ekstedt, M., Söderström, M., Åkerstedt, T., Nilsson, J., Sondergaard H.-P., \& Perski, A. (2006). Disturbed sleep and fatigue in occupational burnout. Scandinavian Journal of Work, Environment and Health, 32, 121-131. http://dx.doi. Journal of Work, Environ
org/10.5271/sjweh.987

Enzmann, D., Schaufeli, W.B., Janssen, P., \& Rozeman, A. (1998). Dimensionality and validity of the Burnout Measure. Journal of Occupational \& Organizational Psychology, 71, 331-350. http://dx.doi.org/10.1111/j.2044-8325.1998. Psychology
tb00680.x

Field, A. (2005). Discovering statistics using SPSS. (2nd edn.). London: Sage Publications.

Gendolla, G.H.E. (2000). On the impact of mood on behavior: An integrative theory and a review. Review of General Psychology, 4, 378-408.

Halbesleben, J.R.B., \& Buckley, M.R. (2004). Burnout in organizational life. Journal of Management, 30, 859-879.http://dx.doi.org/10.1016/j.jm.2004.06.004

Halbesleben, J.R., \& Demerouti, E. (2005). The construct validity of an alternative measure of burnout: Investigating the English translation of the Oldenburg burnout inventory. Work \& Stress, 19(3), 208-220. http://dx.doi. org/10.1080/02678370500340728 
Hobfoll, S.E. \& Freedy, J. (1993). Conservation of resources: A general stress theory applied to burnout. In W.B. Schaufeli, C. Maslach, \& T. Marek (Eds.), Professional
burnout: Recent developments in theory and research (pp. 115-129). Philadelphia, PA: Taylor \& Francis.

Hobfoll, S.E., \& Shirom, A. (1993). Stress and burnout in the workplace: Conservation of resources. In R. T. Golembiewski. (Ed). Handbook of organizational behavior (pp. 41-61). New York, NY: Dekker.

Hobfoll, S.E., \& Shirom, A. (2000). Conservation of resources theory: Application to stress and management in the workplace. In J.W. Lorsch (Ed.), Handbook of organizational behavior (2nd edn.) (pp. 57-81). New York, NY: Marcel Dekker.

Jackson, L.T.R., \& Rothmann, S. (2005). An adapted model of burnout for educators in South Africa. South African Journal of Education, 225(2), 100-108.

Kahn, W.A. (1990). Psychological conditions of personal engagement and disengagement at work. Academy of Management Journal, 33, 692-724. http:// dx.doi.org/10.2307/256287

Kilfedder, C.I., Power, K.G., \& Wells, T.J. (2001). Burnout in psychiatric nursing Journal of Advanced Nursing, 34, 383-396. http://dx.doi.org/10.1046/ j.1365-2648.2001.01769.x

Kristensen, T.S., Borritz, M., Villadsen, E., \& Christensen, K.B. (2005). The Copenhagen burnout inventory: A new tool for the assessment of burnout. Work and Stress, 19(3), 192-207. http://dx.doi.org/10.1080/02678370500297720

Leiter, M.P., \& Maslach, C. (2001). Burnout and health. In A. Baum, T.A. Revenson, \& J.E. Singer (Eds.), Handbook of health psychology (pp. 415-422). Hillsdale, $\mathrm{NJ}$ : Erlbaum.

Malach-Pines, A. (2005). The burnout measure, short version. International Journal of Stress Management, 12(1), 78-88. http://dx.doi.org/10.1037/1072-5245.12.1.78

Maslach, C. (1993). Burnout: A multidimensional perspective. In W.B. Schaufeli, C. Maslach, \& T. Marek (Eds.), Professional burnout: Recent developments in theory and research (pp. 19-32). Philadelphia, PA: Taylor \& Francis.

Maslach, C., \& Jackson, S.E. (1981). The measurement of experienced burnout. Journal of Organizational Behavior, 2(2), 99-113.

Maslach, C., \& Jackson, S.E. (1986). The Maslach burnout inventory. (2nd edn.). Palo Alto, CA: Consulting Psychologists Press. http://dx.doi.org/10.1002/ job.4030020205

Maslach, C., \& Leiter, M.P. (1997). The truth about burnout. San Francisco, CA: Jossey-Bass.

Maslach, C. (1998). A multidimensional theory of burnout. In C.L. Cooper (Ed.) Theories of organizational stress (pp. 68-85). Oxford, U.K.: Oxford University Press.

Maslach, C., \& Schaufeli, W.B. (1993). Historical and conceptual development of burnout. In W. Schaufeli, C. Maslach, \& T. Marek (Eds.), Professional burnout: Recent developments in theory and research (pp. 1-16). Philadelphia, PA: Taylo \& Francis.

Maslach, C., Schaufeli, W.B., \& Leiter, M.P. (2001). Job burnout. Annual Review of Psychology, 52, 397-422. http://dx.doi.org/10.1146/annurev.psych.52.1.397

Matsumoto, D., \& Van de Vijver, F.J.R. (Eds.) (2011) Cross-cultural research methods in psychology. New York, NY: Cambridge University Press.

Mellenbergh, G.J. (1982). Contingency table models for assessing item bias. Journal of Educational Statistics, 52, 397-422.

Nunnally, J.C., \& Bernstein, I.H. (1994). Psychometric theory. (3rd edn.). New York, NY: McGraw-Hill.

Osipow, S.H., Doty, R.E., \& Spokane, A.R. (1985). Occupational stress, strain and coping across the life span. Journal of Vocational Behavior, 27, 98-108. http:// dx.doi.org/10.1016/0001-8791(85)90055-7

Pallant, J. (2010). SPSS survival manual: A step by step guide to data analysis using SPSS program. (4th edn.). New York, NY: McGraw Hill.

Pearse, N. (2011). Deciding on the scale granularity of response categories of Likert type scales: The case of a 21-point scale. The Electronic Journal of Business Research Methods, 9(2), 159-171.

Pines, A.M. (1993). Burnout: An existential perspective. In W. Schaufeli, C. Maslach, \& T. Marek (Eds.), Professional burnout (pp. 33-52). Washington, DC: Taylor \& \&rancis.

Pines, A.M. (1996). Couple burnout: Causes and curses. New York, NY: Routledge.

Pines, A.M. (2005). The burnout measure short version (BMS). International Journal of Stress Management, 12, 78-88. http://dx.doi.org/10.1037/1072-5245.12.1.78

Pines, A., \& Aronson, E. (1988). Career burnout: Causes and cures. New York, NY: Free Press.

Pines, A., Aronson, E., \& Kafry, D. (1981). From tedium to personal growth. New York, NY: Free Press.

Poortinga, Y.H. (1989). Equivalence of cross-cultural data: An overview of basic issues. International Journal of Psychology, 24, 737-756. http://dx.doi. org/10.1080/00207598908247842

Pretorius, L. (2007). Resilience, self-efficacy and burnout of employees in a chemical organisation. Unpublished master's dissertation, Humanities, North-West University, Vanderbijlpark, South Africa.

Qiao, H., \& Schaufeli, W.B. (2011) the convergent validity of four burnout measures in a Chinese sample: A confirmatory factor-analytic approach. Applied Psychology: An International Review, 60(1), 87-111. http://dx.doi.org/10.1111/ j.1464-0597.2010.00428.x
Republic of South Africa. (1998). Employment Equity Act (Act no. 55 of 1998). Government Gazette 400(19379). Cape Town, South Africa: Government Printers.

Rothmann, S. (2003). Burnout and engagement: A South African perspective. SA Journal of Industrial Psychology, 29, 16-25. http://dx.doi.org/10.4102/sajip. v29i4.121

Rothmann, S. \& Barkhuizen, N. (2008). Burnout of academic staff in South African higher education institutions. South African Journal of Higher Education, 22(2) 439-456.

Salkind, N.J. (2009). Exploring research. (7th edn.). Upper Saddle River, NJ: Pearson Education, Inc.

Schaufeli, W.B. (2003). Past performance and future perspectives of burnout research. SA Journal of Industrial Psychology, 29(4), 1-15. http://dx.doi. org/10.4102/sajip.v29i4.127

Schaufeli, W.B., \& Enzmann, D. (1998). The burnout companion to the study and practice: A critical analysis. London: Taylor \& Francis.

Schaufeli, W.B., \& Greenglass, E.R. (2001). Introduction to special issue on burnout and health. Psychology and Health, 16(5), 501-510. http://dx.doi. org/10.1080/08870440108405523

Schaufeli, W.B., Leiter, M.P., \& Maslach, C. (2009). Burnout: 35 years of research and practice. Career Development International, 14(3), 204-220. http://dx.doi. org/10.1108/13620430910966406

Schaufeli, W.B., Leiter, M.P., Maslach, C., \& Jackson, S.E. (1996). Maslach burnout inventory - General survey (MBI-GS). In C. Maslach, S.E. Jackson, \& M.P. Leiter (Eds.), MBI-Test Manual (3rd edn.) (pp. 191-215). Palo Alto, CA: Consulting Psychologists Press.

Schaufeli, W.B., Maslach, C., \& Marek, T. (1993). The future of burnout. In W.B. Schaufeli, C. Maslach, \& T. Marek (Eds.), Professional burnout: Recent developments in theory and research (pp. 33-52). Philadelphia, PA: Taylor \& Francis.

Schaufeli, W.B., \& Van Dierendonck, D. (1993). The construct validity of two burnout measures. Journal of Organizational Behavior, 14, 631-647. http://dx.doi. measures. Journal of Organ
org/10.1002/job.4030140703

Shinn, M. 1982. Methodological issues: Evaluating and using information. In W.S. Paine (Ed.), Job stress and burnout. Beverly Hills, CA: Sage.

Shirom, A. (1989). Burnout in work organizations. In C.L. Cooper, \& I.T. Robertson (Eds.), International review of industrial and organizational psychology (pp. 25-48). Chichester: Wiley.

Shirom, A. (2003). Job-related burnout. In J.C. Quick, \& L.E. Tetric (Eds.), Handbook of occupational health psychology (pp. 245-265). Washington DC: American Psychological Association. http://dx.doi.org/10.1037/10474-012

Shirom, A., \& Ezrachi, Y. (2003). On the discriminant validity of burnout, depression and anxiety: A re-examination of the burnout measure. Anxiety, Stress, and Coping, 16, 83-97. http://dx.doi.org/10.1080/1061580021000057059

Shirom, A., \& Melamed, S. (2005). Does burnout affect physical health? A review of the evidence. In A.G. Antoniou, \& C.L. Cooper (Eds.), Research companion to organisational health psychology (pp. 599-622). Northampton, MA: Edward Elgar Publishing Ltd. http://dx.doi.org/10.4337/9781845423308.00049

Shirom, A., \& Melamed, S. (2006). A comparison of the construct validity of two burnout measures in two groups of professionals. International Journal of Stress Management, 13(2), 176-200. http://dx.doi.org/10.1037/1072-5245.13.2.176

Sonnentag, S. (2005). Burnout research: Adding an off-work and day-level perspective. Work and Stress, 19(3), 217-275.

Spector, P.E. (2006). Method variance in organizational research: Truth or urban legend? Organizational Research Methods, 9(2), 221-232. http://dx.doi. org/10.1177/1094428105284955

SPSS Statistics for Windows version 21.0 [Computer software] (2012). Armonk, NY: IBM Corp.

Storm, K., \& Rothmann, S. (2003). A psychometric analysis of the Utrecht work engagement Scale in the South African police service. SA Journal of Industrial Psychology, 29(4), 62-70. http://dx.doi.org/10.4102/sajip.v29i4.129

Tabachnick, B.G., \& Fidell, L.S. (2001). Using multivariate statistics. (4th edn.). Boston, MA: Allyn and Bacon.

Tremblay, M.A., \& Messervey, D. (2011). The job demands-resources model: Further evidence for the buffering effect of personal resources. South African Journal of Industrial Psychology, 37(2), 1-10.

Trochim, W.M. (2006). The research methods knowledge base. (2nd edn.). Retrieved October 20, 2006, from http://www.socialresearchmethods. net/kb/

Van de Vijver, F., \& Leung, K. (1997). Methods and data-analysis for cross-cultural research. Thousand Oaks, CA: Sage.

Van de Vijver, F., \& Rothmann, S. (2004). Assessment in multicultural groups: The South African case. SA Journal of Industrial Psychology, 30(4), 1-7. http:// dx.doi.org/10.4102/sajip.v30i4.169

Wager, T.D., Phan, K.L., Liberzon, I., \& Taylor, S.F. (2003). Valence, gender, and lateralization of functional brain anatomy in emotions: A meta-analysis of findings from neuroimaging. Neurolmage, 19, 513-531.

Yeh, W., Cheng, Y. Cheng, C., Hu, P., \& Kristensen, T.S. (2007). Psychometric properties of the Chinese version of Copenhagen burnout inventory among employees in two companies. International Journal of Behavioral Medicine, 3 , 126-133. http://dx.doi.org/10.1007/BF03000183 